\title{
The gender difference and education enrollment in Rajasthan
}

\author{
${ }^{1 .}$ Ibraheim Eldai Mohamed, ${ }^{2}$. Dr.Vinita Singh \\ Department of sociology, humanities studies School, Nims University
}

\begin{abstract}
Based on the responses ten Semi-structured interview schedules with the education administrators in Rajasthan and questionnaire of 180 students, 120 teachers, from secondary and high secondary students and 100 common people from Jaipur in Rajasthan state, this article investigates the role of gender differences in education enrollment. Several indicators are considered and investigated using parametric technique. Given the overall structure of Rajasthan society, the results indicate that the gender differences plays a major role in education enrollment, the girl have less chance in education, while there is progress and increase in girls clubbing numbers during the last 10 years .
\end{abstract}

\section{Introduction:}

This paper provides an account of gender equity in schooling in Rajasthan, with a particular emphasis on schooling; it aims to clear those social factors affecting both girls and boys in Rajasthan and the types of initiatives needed to secure meaningful and sustainable method to schooling for all boys and girls without distinction.

First section, the paper will supply with background of role of gender in education in Rajasthan. There then follows social factors that controlled in education according to gender. Both data and research literature are analyzed to clarify the interlocking nature of educational inclusions and exclusions, viewing gendered access alongside issues, Such as education of children belonging to scheduled caste, scheduled tribes and Muslims, disability, poverty and child labour. Supply-side issues are also discussed in terms of educational provision and gendered schooling practices.

In recent times, there has been widespread debate on how education is the most effective means in impacting and re-orienting gender stereotypes and traditional gender roles; and on its role in changing traditional mindset in society. The education system today promotes a linear assembly line mindset, while recent advances in technology make it imperative to encourage a different non-linear mindset among young people breaking across all economic groups. ${ }^{1}$

In this regard the present paper would like to make an attempt to study the status of school education covering primary, and secondary school education focusing on the gender differentials those exists. It also makes an attempt to identify the socio-cultural and economic factors those are significantly affecting the school education. Social exclusion being a process, the paper would like to consider the existing gender differentials in school education in the framework of exclusion and tries to suggest inclusive measures.

\section{The Objective of the study:}

1) To determine the role of education as a catalyst in raising the awareness of gender about education as a right.

2) To find out the current awareness of gender equality in education and the human rights in schools, especially rural girls under fourteen.

3) To know the current status of girls' education, in the state of Rajasthan

4) To recognize the real reasons that stand in front of girls' education

\section{Methodology:}

The present study is an attempt to discuss the role of the gender differences in the school education in Rajasthan. The study also focused on the contemporary data on some key parameters of school education in Rajasthan. In this study, secondary data has been taken into consideration of Rajasthan education department annual reports, on the key parameters of school education in Rajasthan. The primary data collected from number of secondary and higher secondary, enrolment at different stages (Classes I-XII) in schools, in addition to common people from urban and rural area and education leaders in Rajasthan education department, The

\footnotetext{
${ }^{1}$ Charu Walikhanna, report of expert committee on gender and education, national commission for women 4 , Deen Dayal UpAdhyaya marg, New Delhi
} 
researcher had used interview to deal with the education administrators about the study matter, and used questionnaire for teachers, students and common people, addition to direct observation.

\section{Background to Gender in Education in India}

The Indian society is characterized by high degree of structural inequalities in reference to caste, ethnicity, gender, religion, class and various other forms of social exclusion. The inherent networks operate to a great extent and results in deprivation and discrimination. The discrimination has to be considered very seriously while dealing with deprivation or inequalities in Indian society. Of all the communities it is the Scheduled Castes and Scheduled Tribes followed by the Other Backward Classes are the worst affected and the discrimination that was experienced by these communities is immense. ${ }^{2}$

Despite of the great damage done to these communities the peoples movements and assertions and the icons like Dr. Babasaheb Bhimrao Ambedkar, Jyotiba Phule and others contributed for the uplift of the masses from the oppressed communities while considering women's education in particular.

In this context it would be very relevant to mention by Sen Amartya, he advocates that social exclusion represents an important loss of capability in its own right as well as being a cause of other deprivations those further remove the individual or group from access to the good life or the means to acquire it. ${ }^{3}$

Lack of knowledge is a result of denial to access it. The denial is a result of socio-cultural, political and historical processes in Indian society and its social structure, where discrimination is institutionalised through stratification and hierarchy in the form of caste, tribe and gender. When the members of the community are denied the access to knowledge that is imparted through educational institutions of the modern times have to challenge the implications of the age old socio-cultural processes perpetuated through institutions. In order to tackle the menace the Constitution of India has provided certain measures in the form of fundamental rights to promote equal representation. The recent Right to Education Act, is a very new measure, its inclusion has to be tested in future.

Education being one of the most important factors, for an overall development of an individual and society, it is important to see the status of school education. School education being the foundation for rest of the education, it is important to consider the level of education while considering the enrolment. As the gender disparities continue to exist and several measures being attempted to overcome the situation it becomes essential to understand the differentials those exist in enrolment in schools. ${ }^{4}$

\section{Gender Equity in Education: A Review of Trends and Factors:}

Relation to attendance and dropout, as this review paper goes on to argue, the increased enrolment of girls is widely attributed to the increasing number of 'informal' or 'non- formal' education programmes, and associated with a public sector that is considered widely to have failed in terms of delivery of quality education. If the increasing enrolment of girls is taking place in an environment of fragmented provision and poor quality public delivery, then the question remains of the value and success of current policy and programmatic interventions in relation to closing the gender gap in a sustainable way.

Unfortunately, this question cannot be easily answered because of the dearth of evaluation studies of the impact of education programmes on closing gender gaps. As Ramachandran notes:

A large volume of data has been generated for the DPEP districts and the programme. However, there is hardly any critical reflection on issues that determine class transitions or primary school completion rates. The complex social and gender equity issues that frame primary education are hardly addressed, especially those relating to household decision-making on education, nor is data that is generated concomitantly disaggregated by gender as well as social groupings.

The trend in number of girls per thousand boys enrolled in the last four years from 2006-07 to 2009-10 reveals that there was a decline from 818 girls per thousand boys in 2006-07 to 813 in 2009-10, which has recently increased to 874 girls per 1,000 boys in 2009-10.

Figure 1: Trends in Gender-wise enrollment in Rajasthan, DISE, 2006- 10 (in girls per 1,000 boys enrolled)

\footnotetext{
${ }^{2}$ Satya Venkata Siddhardha Kumar.D, Gender Differentials and Social Exclusion in School Education in India, National seminar organized by CSSEIP, cusat on 5th January 2010, p2

${ }^{3}$ Sen, Amartya. (2004). "Social Exclusion Concept Application Scrutiny, New Delhi: Critical Quest.

${ }^{4}$ Tailor, R. (2007). "Participation of Scheduled Castes Children of the Primary Stage in India". New Delhi:

Journal of Indian Education.
} 


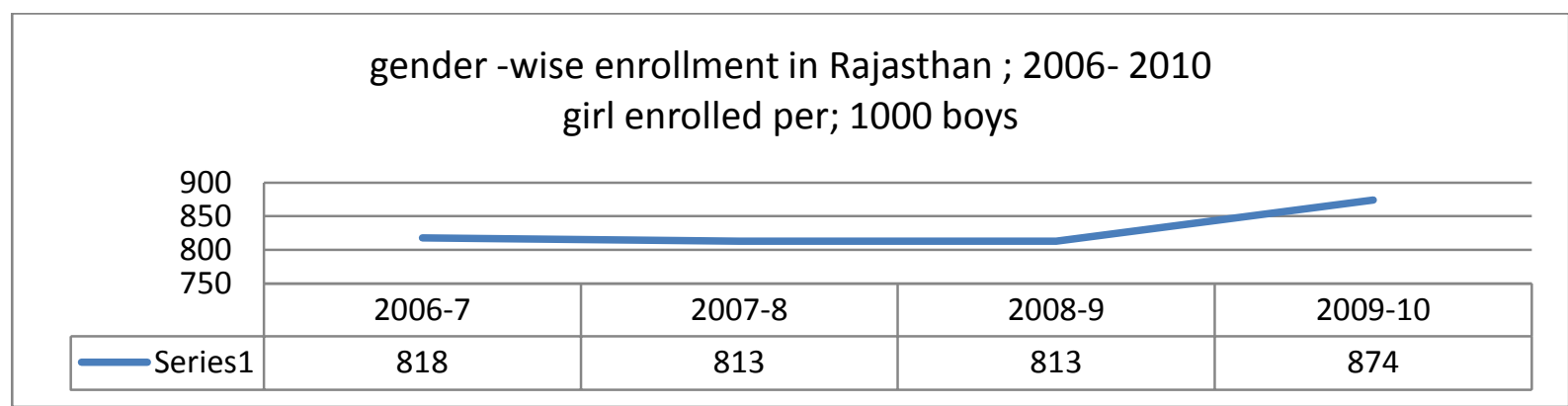

((Source: post enumeration survey of 5 percent sample checking of DISE data in three districts of churu, dungarpur \& Jhalawar in Rajasthan: 2010-11))

With the exception of the Mahila Samakhya project which has a clearly articulated and carefully defined approach to addressing gender inequality through women's empowerment, assessments of the government programme and institutional performance on gender have been measured narrowly, primarily through quantitative assessments of change. Changes in data are used to hypothesis about the changing patterns of gendered access to education. However, few qualitative studies have been carried out to test hypotheses about what drives change in female education, and what lies behind the changing nature of demand for female schooling. Hence, as below, this review of literature draws upon quantitative data in the main to present an overview of issues in female education in India.

Figure 2: Literacy Rates in India and Rajasthan by Gender, Census 2011

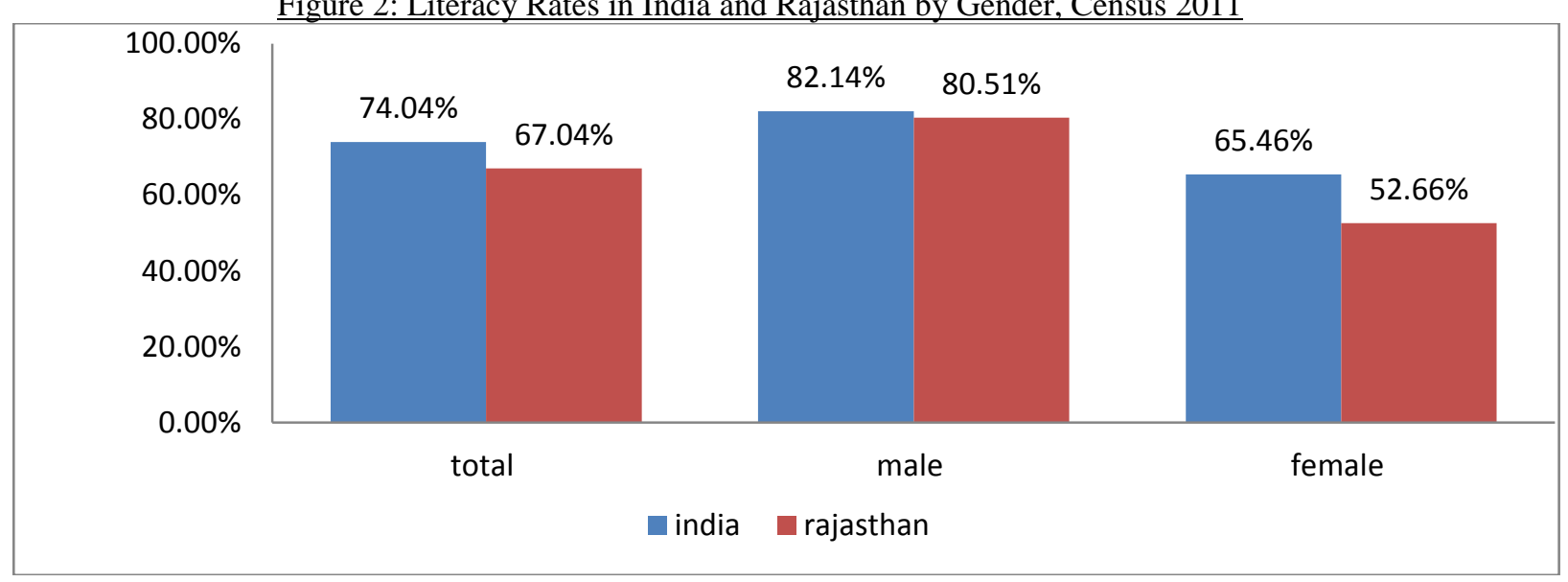

Source: Census of India, 2011 (Provisional)

Gender-wise, there is a big gap between male and female literacy. In total literacy, Rajasthan ranks 33rd amongst the 35 states and union territories and in case of male and female literacy it ranks 27th and 35th respectively.

\section{Findings and Recommendations:}

Regarding to below table the gender difference play a major role in education clubbing in Rajasthan state

Figure (3) gender difference and education

\begin{tabular}{|l|l|l|l|l|l|l|l|l|l|l|}
\hline $\begin{array}{l}\text { Respondents family education } \\
\text { background }\end{array}$ & \multicolumn{2}{l|}{ Do you think that gender difference plays a role in education? } & Total \\
\hline & Yes & I think that & \multicolumn{1}{l|}{ I don't know } & No & \\
\hline Uneducated & 3 & $60 \%$ & 0 & 0 & 0 & 0 & 2 & $40 \%$ & 5 \\
\hline Primary & 6 & $66.7 \%$ & 0 & 0 & 0 & 0 & 3 & $33.3 \%$ & 9 \\
\hline Secondary & 17 & $94.4 \%$ & 0 & 0 & 0 & 0 & 1 & $5.6 \%$ & 18 \\
\hline Graduate & 51 & $56 \%$ & 14 & $15.9 \%$ & 2 & $2.3 \%$ & 21 & $23.8 \%$ & 88 \\
\hline Total & 77 & & 14 & & 2 & & 27 & & 120 \\
\hline
\end{tabular}




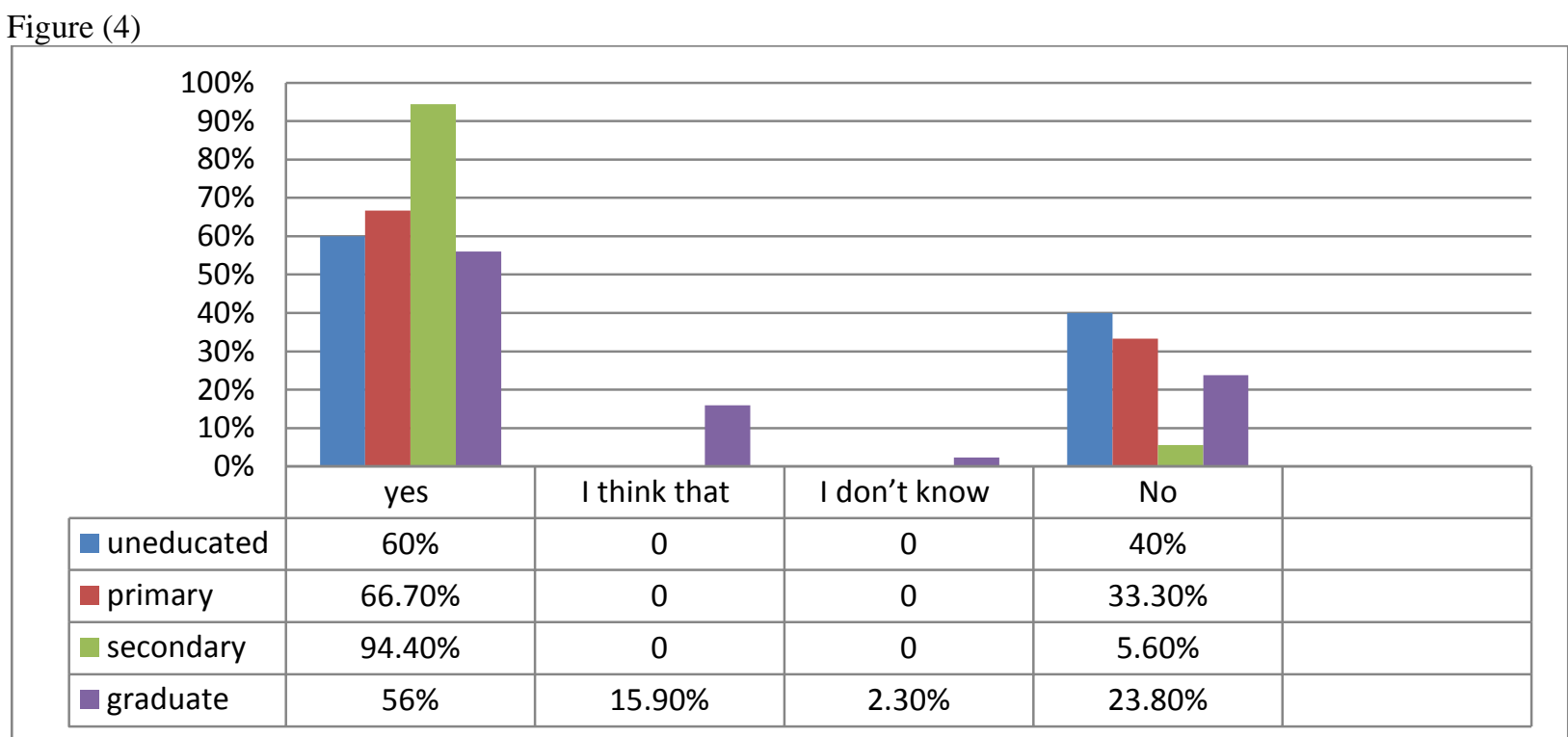

Figure (4) states gender difference in education clubbing regarding respondents from family education background.

120 teachers were the sample for the study. Of which 5 (I.e., 4.2\%) teachers were from uneducated family background, 9 (I.e., $7.5 \%$ ) teachers primary education family background, 18(I.e., 15\%) teacher family were educated up to secondary level, and 88 (I.e., 74\%) teachers from graduate education family background.

$60 \%$ teachers from uneducated family background said that gender difference plays a role in education in Rajasthan state, while $40 \%$ said that gender difference plays No role in education.

Nearly $67 \%$ of teachers from the primary education family background said that gender difference plays a role in education, whereas $33 \%$ found that gender difference did not play any role in education.

About $95 \%$ of the teachers from secondary education background family said that gender difference plays a role in education in Rajasthan.

$56 \%$ of the teachers from graduation education background family said that gender difference plays a role in education while 5\% said gender did not play any role in education and about $24 \%$ said gender difference did not play a role in education. We should say that gender difference plays a role in education in Rajasthan state.

- Gender difference plays a role in education in Rajasthan state especially in rural area, that regarding to the community culture values such earlier girl's marriage.

- After decades of attention to gender matters in the Rajasthan state India, there are important achievements last 10 years, across Rajasthan schools and there is much greater awareness of gender equality as an educational issue than there was in the past.

- Standard economics level is has direct relation with the education level and it will obstacle factor for people to benefits from the education, especially girls' parents focusing in boys educating more than girls, so with the bad economic status and high expenses of education girls had less chance.

\section{Recommendations:}

Based on the above analysis, following are the recommendations to promote gender equity in the field of education in Rajasthan state:

* Establish active program to encourage girls' participation in education, with increasing the proportion of women teachers to responsible for the education of the girls in the village.

* Government and NGOs have undertaken to provision annually scholarships to meritorious girls, provision of free text books, and all the education expenses.

* Make awareness about the important of education and how it increases the productivity of individuals and therefore lead to higher earnings, which can change their socioeconomic status especially in the poor communities.

\section{Conclusions:}

The data analysis reveals the study the role in education enrollment, itI had been found that the gender differences plays a major role in education clubbing in Rajasthan state, while there is improvement in participation of girls during the last 10 years, and also there is increase in enrolment of girls has been more significant at the upper primary level as compared to primary level, progress has been made. 
There has also been observe there is increase in the girls enrolment especially in rural areas. Whereas enrolment of girls in all areas grew up in rural areas it increased in primary schools and upper primary schools during the same period.

While a large number of girls still face difficulties in entering school and continuing their studies. There is also a significant gender gap in educational participation in Rajasthan, the reasons that behind the dropping girls out of the schools by parents and society in general; the vision of girls' education; include incapable of the family to undertake girls education expenses, poverty; and the practice of child marriage. The socioeconomic status of the families had a directly relation to the girl's education level in the family, that means economic and culture of the family play a center role in the family girl situation.

To battle the girls education wastage the government and community have to take this issue in series way and establish the legislation to product girl against the community culture with active program.

\section{References:}

[1]. Charu Walikhanna, report of expert committee on gender and education, national commission for women 4, Deen Dayal UpAdhyaya marg, New Delhi

[2]. Satya Venkata Siddhardha Kumar.D, Gender Differentials and Social Exclusion in School Education in India, National seminar organized by CSSEIP, cusat on 5th January 2010, p2

[3]. Sen, Amartya. (2004). "Social Exclusion Concept Application Scrutiny, New Delhi: Critical Quest.

[4]. Tailor, R. (2007). "Participation of Scheduled Castes Children of the Primary Stage in India". New Delhi: Journal of Indian Education.

[5]. Census of India, 2011 (Provisional).

[6]. post enumeration survey of 5 percent sample checking of DISE data in three districts of churu, dungarpur \& Jhalawar in Rajasthan: 2010-11 